\title{
¿QUÉ SON LAS CONSTANTES LÓGICAS?
}

\author{
MARÍa José Frápolli \\ Departamento de Filosofía I \\ Universidad de Granada \\ mjfrapolli@gmail.com
}

RESUMEN: El artículo ofrece una caracterización de las constantes lógicas, [CL], analizando el significado de las expresiones que son sus contrapartidas en el lenguaje natural. [CL] recoge los rasgos sintácticos, semánticos y pragmáticos individualmente necesarios y conjuntamente suficientes para que una expresión sea una constante lógica. Se obtendrá la siguiente conclusión: que la lista de las expresiones que habitualmente se consideran constantes lógicas no comparten rasgos relevantes desde el punto de vista del significado que justifiquen su tratamiento como un grupo homogéneo. Sólo algunos usos del condicional, de la negación y de ciertos cuantificadores son constantes lógicas genuinas.

PALABRAS CLAVE: expresivismo, marcador inferencial, pragmatismo, predicable de orden superior, regla

SUMMARY: The aim is to offer a characterization of logical constants [LC] focusing on the meaning of their natural language counterparts. [LC] includes syntactic, semantic, and pragmatic aspects which are individually necessary and jointly sufficient for an expression to score as a logical constant. The conclusion reached at is the following: that the expressions included in the traditional list of logical constants do not share relevant features from the point of view of their meaning that justify their treatment as a homogeneous group. Only some uses of conditional, negation and quantifiers are genuine logical constants.

KEY WORDS: expressivism, inference marker, pragmatism, higher-order predicable, rule

\section{El problema}

¿Qué problema filosóficamente relevante plantean las constantes lógicas? A la expresión "constante lógica" solemos asociar una lista de nociones entre las que se incluyen, al menos, las siguientes: negación, conjunción, disyunción, condicional, bicondicional, cuantificador universal y cuantificador existencial. A veces se añaden otras nociones como el relator de identidad, el relator de pertenencia, el operador lambda y también cuantificadores no estándar, operadores temporales, modales y epistémicos y la lista puede continuar. Además, cuando se nos pregunta qué es la lógica, todos nosotros ofrecemos aproximadamente la misma respuesta: la lógica es la ciencia que estudia la validez de los argumentos, cuyo concepto central es el de consecuencia lógica. 
La tarea filosófica de definir las constantes lógicas se ha abordado apelando a todos los niveles de análisis del lenguaje. Hay definiciones que destacan las propiedades estructurales de las expresiones y de los lenguajes en los que aparecen. Dentro de este tipo, las propuestas invariantistas son las que han recibido un apoyo más generalizado. El origen es Alfred Tarski (1966/1986), y en la actualidad Gila Sher (1991 y 2003) es una de sus más activas defensoras. Otras definiciones tienen en cuenta nociones semánticas como la preservación de la verdad o la preservación de la demostrabilidad. Las propuestas inferencialistas, que tienen su origen en Gerhard Gentzen, y posteriormente han sido defendidas por Ian Hacking (1979), Christopher Peacocke (1988) y Michael Dummett (1977), pertenecen a esta categoría y se distinguen por identificar el significado de las constantes lógicas con las reglas de introducción y eliminación que gobiernan su uso dentro de los cálculos. Dummett explica: "El significado de cada constante lógica se da al especificar, para cualquier oración en la que esta constante sea el operador principal, qué cuenta como una demostración de esta oración, asumiendo que ya sabemos lo que cuenta como una demostración de cualquiera de sus constituyentes" (Dummett 1977, p. 8). ${ }^{l}$ Las reglas de introducción y eliminación constituyen el significado de las constantes lógicas en el mismo sentido en que las condiciones de aplicación de una expresión y las consecuencias de su aplicación permiten, según el inferencialismo semántico, individuar el contenido de los conceptos no lógicos. Hay también propuestas mixtas, como la de Peacocke (1976, p. 223), quien hace descansar la determinación de lo que sea una constante lógica en dos criterios: un criterio sintáctico y un criterio epistémico. El criterio sintáctico nos dice que las constantes lógicas son formadoras de expresiones predicativas, y el criterio epistémico nos informa que se puede conocer a priori cuáles son las secuencias que satisfacen las expresiones en las que aparecen constantes lógicas. Por último, también las hay que centran la discusión acerca de qué sea una constante lógica en los propósitos de los hablantes al usarlas. Estas últimas las consideramos pragmáticas. Desde esta perspectiva, Ken Warmbrõd (1999, pp. 516 y ss.) caracteriza las constantes lógicas por su contribución a la tarea de sistematizar teorías científicas, una caracterización que recuerda la que Frank Ramsey ofreció (1928/2005, p. 418) para el caso de los condicionales generalizados, y que rechazó posteriormente (1929/2005, p. 427). Robert Brandom (1994, cap. 2; 2000, cap. 1) propone una fundamentación pragmática normativa para los casos

${ }^{1}$ La traducción de las citas originalmente en inglés es mía en todos los casos. 
del condicional y la negación, y Mario Gómez-Torrente (2002 y 2007) sugiere algunos aspectos que una caracterización pragmática de las constantes debería tener en cuenta, aunque sin ofrecer una propuesta específica. En medio de todo esto, todavía hay apasionados debates acerca de si es posible ofrecer una definición de constante lógica que sea, a la vez, matemáticamente adecuada y filosóficamente relevante, como el protagonizado por Gómez-Torrente (2002) y Sher (2003). Sin embargo, a pesar de toda esta actividad teórica e intercambio de propuestas y contrapropuestas, se puede decir siguiendo a Warmbrõd (1999, p. 503) que "no hay todavía un consenso asentado acerca de lo que hace a un término ser una constante lógica ni siquiera acerca de a qué términos debería de reconocérseles este estatus".

En este contexto, mi objetivo es ofrecer una propuesta pragmática que tome en consideración para qué usan constantes lógicas los hablantes de una lengua. La idea general que guía la presente propuesta es que la cuestión de qué sea una constante lógica exige un completo cambio de escenario. Exige, entre otras cosas, abandonar el camino iniciado por Tarski y volver a los orígenes de la lógica moderna, a C.S. Peirce y al Frege de Begriffsschrift.

\section{Diversos tipos de lógica}

La palabra "lógica" se aplica a disciplinas y proyectos muy diversos. La tarea de especificar cuáles son los rasgos que hacen que determinadas expresiones de nuestro lenguaje hayan sido destacadas como constantes lógicas exige que tomemos una decisión acerca de a qué tipo de proyecto teórico vamos a llamar "lógica". Y ha habido varios en los últimos ciento cincuenta años, conviviendo a veces en el mismo autor. Tarski, en "What Are Logical Notions?" (1966/1986), propone su definición de constante lógica inspirándose en el trabajo de Felix Klein sobre nociones geométricas. A propósito del debate decimonónico acerca de si la lógica trata de clases o de propiedades, Tarski ofrece su punto de vista:

Se ha dicho muchas veces, especialmente por lógicos matemáticos, que nuestra lógica es realmente una lógica de extensiones. Esto significa que dos nociones no pueden distinguirse lógicamente si tienen la misma extensión, incluso aunque sus intensiones sean diferentes. Como se dice habitualmente, no podemos distinguir lógicamente propiedades de clases. Ahora, a la luz de nuestra propuesta resulta que nuestra lógica es menos incluso que una lógica de la extensión, es una lógica del número, de las relaciones numéricas. (Tarski, 1966/1986, p. 151) 
Las nociones lógicas, defiende Tarski, pueden definirse de manera similar a como se definen las nociones geométricas. La lógica es así una ciencia del mismo tipo que las diversas teorías geométricas, aunque con un mayor grado de abstracción que se deriva del hecho de que las relaciones lógicas dependen exclusivamente de relaciones numéricas, relaciones que ni siquiera tienen que ver con la constitución particular de las extensiones de los conceptos, sino simplemente con sus tamaños. Para Tarski, la lógica es "una ciencia, un sistema de oraciones verdaderas, y [...] las oraciones contienen términos que denotan ciertas nociones, las nociones lógicas" (Tarski 1966/1986, p. 145). Las nociones lógicas son objetos invariantes bajo toda trasformación del universo sobre sí mismo, defiende Tarski en este artículo (p. 149). Si se aplica esta caracterización a la jerarquía de tipos, se obtienen los siguientes resultados: en el nivel de los individuos, ninguna noción es invariante en el sentido indicado, en el nivel de clases de individuos sólo son invariantes la clase universal y la clase vacía, si se sigue subiendo en la jerarquía hasta las clases de clases, las únicas relaciones binarias que se ajustan a la caracterización son la identidad y la diferencia. Se puede continuar con relaciones ternarias, cuaternarias, etc., aunque para estos casos Tarski no se pronuncia sobre qué relaciones $n$-ádicas $(n>2)$ serían constantes lógicas. ${ }^{2}$ En definitiva, la lógica es una ciencia como otras y sus objetos son objetos de la jerarquía de tipos: clases y clases de clases. Llamaremos a este proyecto "la concepción de Tarski". Un representante contemporáneo es James Higginbotham, quien define la lógica como "la teoría más general de lo verdadero y lo falso" (Higginbotham 2000, p. 79).

Hay una manera alternativa de entender la tarea de la lógica: no como un sistema de verdades sino como un sistema de transiciones entre proposiciones, transiciones que preservan la verdad (o alguna otra noción). ${ }^{3}$ Esta segunda manera es la que defiende Peirce, así como Frege en Begriffsschrift. En esta obra de 1879, Frege identifica como nociones lógicamente relevantes el condicional, la negación, el cuantificador universal y la identidad de contenido. Estas dos

${ }^{2}$ En "On the Concept of Logical Consequence" (1936/1956), Tarski menciona el condicional y el cuantificador universal como expresiones que deben ser consideradas constantes lógicas (p. 418), y la noción central de la lógica es, en ese artículo, la de consecuencia lógica. Sin embargo, en el artículo sobre nociones lógicas de 1966/1986, las constantes lógicas son clases y la lógica es una teoría que puede formularse axiomáticamente. Hay, en el propio Tarski, una tensión teórica que apoya la idea de que bajo el rótulo de "lógica" coexisten diversos proyectos.

${ }^{3}$ En posiciones cercanas al intuicionismo, como la de Dummett, lo que se preserva es la demostrabilidad; en posiciones pragmáticas, como la de Brandom, lo que se preserva son las habilitaciones para aseverar, y podría haber otras aproximaciones. 
listas, la que Frege ofrece y la que se sigue de la definición de Tarski, no tienen ningún elemento en común, lo que es una razón añadida para dudar de que ambos autores estén tratando el mismo problema. Jaakko Hintikka y Gabriel Sandu, si bien críticos con el proyecto general de Frege, ${ }^{4}$ optan por una caracterización de la lógica cercana a la de Begriffsschrift. Estos dos autores sostienen:

No está nada claro lo que se entiende o debería entenderse por lógica. Lo que sí resulta razonable, sin embargo, es identificar la lógica con inferencias y relaciones inferenciales. [...] De ahí el porqué de que la teoría relativa a cualquier parte de la lógica parezca adquirir de manera característica la forma de conjunto de reglas de inferencia. (Hintikka y Sandu 2007, p. 15)

Ésta es la visión de la lógica que se codifica en los cálculos de deducción natural, propuestos de manera independiente por Gentzen y Jaskowski en los años 1930 (véase, por ejemplo, Pelletier 1999). Llamaremos a este proyecto "la concepción Frege". 5

${ }^{4}$ El proyecto de Hintikka y Sandu conocido como la "lógica amigable a la independencia" (independence-friendly logic, IF-Logic) rechaza que la teoría de la cuantificación clásica, i.e., la lógica de Frege, sea un instrumento adecuado para representar estructuras y formas de razonamiento tanto en las matemáticas como en el lenguaje natural. Entre las críticas más serias de la IF-Logic contra la teoría de la cuantificación destacan la exigencia de representación lineal de las fórmulas y de la lectura de izquierda a derecha, que hace que los distintos operadores de una fórmula aparezcan anidados (véase, por ejemplo, Hintikka y Sandu 2007, p. 33). Hintikka argumenta que la noción de alcance del cuantificador, propio de la teoría clásica, en realidad incluye dos nociones distintas: la noción de alcance, que indica cuáles variables van ligadas por qué cuantificador (binding scope), y la noción de alcance, la cual indica qué operador tiene prioridad sobre qué otro (priority scope). La diferencia es necesaria para analizar oraciones con relaciones de dependencia complejas, como es el caso de las llamadas "Donkey-sentences" (véase, por ejemplo, Hintikka 1997).

${ }^{5}$ En Frege también existe tensión entre distintas posiciones acerca de lo que es la lógica. Brandom, siguiendo a Dummett, ha señalado un cambio en Frege a partir de 1892, cuando se mueve desde una concepción inferencial del contenido y una concepción expresiva de las constantes lógicas hacia una teoría general del significado de corte representacionalista (véase Brandom 2000/2002, p. 74). Sí parece haber tensión entre lo que se dice en Begriffsschrift y lo que se dice en obras posteriores en las que se califica a la lógica como la ciencia que debe permitir el reconocimiento de las leyes de lo verdadero (véase, por ejemplo, Frege 1918-1919/1974, p. 136). Aun así, para Frege la lógica no es una de las ciencias, como tampoco lo era para Wittgenstein (Tractatus, 6.13). A lo largo de toda su obra, Frege marcó el contraste entre las ciencias que buscan verdades y la lógica, cuyo objetivo es otro: o bien marcar conexiones seguras entre contenidos juzgables, o bien identificar las leyes del ser verdadero. 
Para la discusión de las constantes lógicas es altamente relevante cuál es la concepción de la lógica que se tiene en mente. El resultado, como hemos visto en los casos de Tarski y Frege, no será el mismo si el objetivo es identificar funciones invariantes que si el objetivo es identificar expresiones que indiquen transiciones preservadoras de la verdad (o de alguna otra noción). La concepción de Frege es la que mejor encaja con la intuición generalizada de que el objeto de la lógica es la validez, en contraste con la verdad lógica, el que deriva de manera más natural de la tesis de que la noción de consecuencia es la noción central de la lógica, y el que respalda la manera en la que mayoritariamente enseñamos lógica a nuestros alumnos.

Las dos concepciones definen proyectos distintos y, por tanto, la palabra "lógica" aplicada a ambos representa un caso de ambigüedad léxica. La lógica en el sentido de Tarski (o lógica-T) es una disciplina dirigida a la obtención de estructuras, organizadas axiomáticamente, cuyos axiomas, las verdades lógicas, son esqueletos formales con características especiales. Estas estructuras contienen "nudos" que denotan objetos abstractos de cierto tipo, las constantes lógicas. Tarski estaba perfectamente consciente de la dificultad de definir estos "nudos" que determinan las estructuras válidas (véase Tarski 1936/1956, p. 418), y estaba asimismo consciente de que su noción de consecuencia dependía de la identificación correcta de los términos que marcan los nudos. La propuesta de Tarski 1966/1986 es que estos términos que, en teoría, deben generar los resultados intuitivamente apropiados respecto de la relación de consecuencia denotan nociones que permanecen invariantes a través de las permutaciones. La lógica-T puede considerarse sin riesgo como una rama de las matemáticas, como lo son las diversas teorías geométricas que sirvieron a Tarski de inspiración.

Por otro lado, la lógica en el sentido de Frege, la lógica-F, es una disciplina dirigida a la obtención de modelos de razonamiento válido. "De estas necesidades", explica Frege, "nació la idea de la presente conceptografía. Por lo pronto, ésta debe servir para probar de la manera más segura la precisión de una cadena de inferencias y para denunciar toda proposición que quisiera colarse inadvertidamente y poder investigarla en su origen" (Frege 1879/1972, p. 3). No es el objetivo de la lógica identificar conjuntos de axiomas, sino definir reglas que permitan realizar transiciones seguras entre contenidos juzgables. Se podría decir que, enfrentadas al problema teórico de definir qué sean las constantes lógicas, la lógica-T se fija fundamentalmente en las razones que las hacen constantes, mientras que la lógica-F se ocupa de las razones que las hacen lógicas. 
No es un argumento contra la distinción entre la lógica-F y la lógica-T el que los cálculos axiomáticos estándar y los cálculos de deducción natural puedan retraducirse uno en otro, o que arrojen el mismo conjunto de teoremas y argumentos válidos. Lo que eso prueba es que todos ellos tienen que responder ante las intuiciones lógicas de sus proponentes y usuarios, y que éstas pueden codificarse de muy distintas maneras. El hecho de que haya propuestas acerca de las constantes que arrojen resultados tan dispares como la lista de Begriffsschrift y la lista de Tarski (1966/1986) es un sólido indicio de que constituyen proyectos teóricos diferentes. Y, desde luego, el hecho de que no se disponga de una definición adecuada de constante, a pesar del extraordinario desarrollo y la proliferación de los cálculos de lógica durante el siglo pasado, debería hacernos pensar que hay algo seriamente equivocado en la manera habitual de aproximación al tema de las constantes lógicas.

Además de la ambigüedad de la palabra "lógica" como nombre propio que se aplica a disciplinas teóricas, "lógica" también se usa como nombre común, con artículo indefinido, para hacer referencia a sistemas formales particulares. La diferencia entre lógica- $\mathrm{T}$ y lógica-F se percibe también en las distintas formas en las que se define qué es una lógica. En la lógica-T, una lógica es un par ordenado que consta de un conjunto de entidades, estructuras, oraciones o fórmulas, y una relación de consecuencia lógica. Para la lógica-T, cualquier estructura axiomática organizada deductivamente cuenta como una lógica. La lógica-F, por el contrario, pone el énfasis en cuáles sean las interpretaciones de los sistemas formales. En el capítulo 1 de su Philosophy of Logics, Susan Haack declara que "la afirmación de que un sistema formal es una lógica depende [...] de que tenga una interpretación de acuerdo con la cual pueda ser vista como si aspirara a representar cánones de argumentos válidos" (Haack 1978, p. 3). En este sentido, qué sea una lógica, o qué sea un cálculo de lógica, depende no tanto de las propiedades formales de la estructura en cuestión como de sus interpretaciones propuestas. Un mismo cálculo puede ser una lógica bajo una interpretación y no serlo bajo otra.

Para el propósito de esclarecer qué es una constante lógica, resulta imprescindible distinguir entre (i) la tarea de entender el significado de las expresiones del lenguaje natural que son las contrapartidas de las constantes lógicas de los cálculos, y (ii) la tarea de entender cómo funcionan los expedientes formales mismos. Si los cálculos de lógica tienen que servir como modelos de razonamiento, las dos tareas tienen que mantener una conexión definida. Para nosotros, la 
cuestión filosóficamente significativa es (i): descubrir por qué los lógicos han seleccionado precisamente ese conjunto (o esos conjuntos) de expresiones, ${ }^{6}$ que sirve(n) también como clase de control para evaluar los resultados de las diversas definiciones de constante lógica que se han propuesto.

\section{Las constantes lógicas del lenguaje natural}

Las disciplinas que tratan del significado de expresiones y conceptos, en su sentido más amplio, son la lingüística y la filosofía del lenguaje. Si el objetivo es entender cómo funcionan las constantes lógicas en los lenguajes naturales, es razonable tomar en consideración los desarrollos y logros de estas disciplinas. Los lógicos con una mayor inclinación formalista que tengan a la lógica-T como su horizonte pueden replicar que la lógica contemporánea se liberó de la gramática de los lenguajes naturales a finales del siglo XIX, y que gracias a esta circunstancia consiguió el grado de desarrollo del que goza en la actualidad. Y tendrían razón al argumentar así; la lógica no está relacionada con la gramática, como Frege nos enseñó en su Conceptografía (1879). En realidad, la lógica no está relacionada con ítems lingüísticos de ningún tipo, ni con oraciones de las lenguas naturales ni con fórmulas de los cálculos artificiales. Los ítems que presentan propiedades lógicas, y que pueden establecer relaciones lógicas con otros, son contenidos juzgables, contenidos que los hablantes expresan mediante el uso del lenguaje. Ésta es la enseñanza de $B e$ griffsschrift. Estos contenidos se denominan también proposiciones, enunciados y, en la terminología de la pragmática contemporánea, lo que se dice.

La lingüística contemporánea ha mostrado interés en el funcionamiento de palabras tales como "y", "no", "pero", "algunos", etc., siguiendo fundamentalmente el trabajo pionero de Grice (Grice 1975).

\footnotetext{
${ }^{6}$ La conectiva "tonk", que Prior introdujo en Prior 1960 aparentemente para mostrar que las reglas de inferencia no pueden proporcionar el significado de las constantes, ha provocado gran debate, y la comunidad filosófica ha aceptado los argumentos de Prior con respeto. Sin embargo, el argumento de Prior es muy débil, como ya lo mostró Stevenson 1961, pues olvida que las reglas de inferencia que definan las constantes han de ser correctas. En cualquier caso, tanto el argumento de Prior como el debate posterior son irrelevantes para mis propósitos. Mi punto de partida son las expresiones que los hablantes de una lengua utilizan en sus prácticas inferenciales y los usos que hacen de estas expresiones. El problema que planteo es por qué los lógicos han seleccionado, de entre todas nuestras palabras, aquellas que corresponden a "no", "o", "si", "luego", etc., para convertirlas en el objeto de su interés. "Tonk" no responde a ningún concepto o regla usado en prácticas reales, por muy buenas razones, como Prior lo mostró.
} 
A través de la introducción de la distinción entre lo que literalmente se dice y lo que se implica pragmáticamente, Grice defendió la identificación del significado de las contrapartidas de las constantes lógicas en el lenguaje natural con las tablas de verdad de la lógica clásica. El plus de contenido que percibimos a veces ligado a estas contrapartidas no forma parte de lo que literalmente se dice; más bien constituye la información cancelable que se conoce como "implicatura". El trabajo de Grice ha inspirado dos maneras diferentes de entender la pragmática. Hay neogriceanos que se mantienen fieles al escenario original e insisten en que el significado de estas expresiones se agota en las tablas de verdad y en que su uso produce implicaturas más o menos por defecto. Y los hay que, como los teóricos de la relevancia (Sperber y Wilson 1986) y los defensores de la pragmática de las condiciones de verdad, como François Recanati (1993, 2001, 2002, 2004, 2007 y 2010) y Robin Carston (1993 y 2002), defienden la tesis de que lo que se dice (la proposición expresada mediante una proferencia) está infradeterminado por el significado lingüístico de las expresiones, incorporando indefectiblemente elementos del contexto. Las proposiciones (lo que se dice, el contenido juzgable) son los ítems que portan las propiedades y relaciones lógicas, y estas propiedades y relaciones las tienen a ellas como sus argumentos.

El problema de las constantes lógicas es cómo caracterizar el significado de las expresiones que codifican propiedades y relaciones lógicas entre portadores de verdad. En primer lugar, hay que destacar que las constantes lógicas son expresiones predicativas, funcionales, que incorporan "ranuras" o "lugares vacíos" que deben rellenarse con proposiciones y contenidos conceptuales. Las relaciones de consecuencia lógica o de incompatibilidad no se dan entre estructuras sin interpretar, sino entre contenidos completos (que posteriormente pueden representarse en los cálculos de diversas maneras). En segundo lugar, si las constantes lógicas expresan las conexiones entre contenidos juzgables, sus significados no deben afectar los contenidos mismos que conectan. Veamos cómo podemos dar una explicación teóricamente sostenible de estas dos afirmaciones generales.

Lo que los lógicos entendemos por constantes lógicas representa un subconjunto de lo que los lingüistas contemporáneos denominan "marcadores discursivos" o "conectivas del discurso". Entender cómo funcionan estos marcadores discursivos desde el punto de vista de sus significados nos facilitará la comprensión del papel que las constantes lógicas desempeñan en las inferencias en las que aparecen. Es aconsejable abordar el análisis del significado de marcadores, conectivas y constantes en dos pasos. En el paso 1, es deseable tener claro lo que 
estas expresiones no hacen; ésta sería una caracterización negativa de su significado. En el paso 2, la caracterización negativa debe complementarse con una caracterización positiva del efecto que tienen en la significación general de los actos de habla en los que aparecen. La respuesta general al paso 1 consiste en la tesis de que palabras y expresiones como "no", "pero", "si", "por lo tanto", "luego", "todos", etc., no suponen la adición de un componente identificable a lo que es el contenido explícito expresado por las proferencias. Esta idea ha aparecido históricamente ligada a autores muy diversos. Es la tesis que manifiesta Wittgenstein en el Tractatus, proposición 4.0312, cuando dice: "Mi pensamiento fundamental es que "las constantes lógicas' no representan."

Una vía alternativa de explicar (1) y (2) consiste en asumir que los marcadores, conectivas y constantes no expresan conceptos, si por "concepto" entendemos los ingredientes de las proposiciones. En la terminología de la teoría de la relevancia diríamos que estas expresiones no poseen significado conceptual (Blakemore 1987, 1989, 1992, 2000, 2002, Blakemore y Carston 2005). La distinción que se plantea entonces es la que se establece entre expresiones que significan conceptos y expresiones que no significan conceptos. En la época medieval es la intuición que distingue entre expresiones que expresan categorías y expresiones sincategoremáticas. Las constantes lógicas son de este último tipo. Las nociones que no expresan conceptos poseen otro tipo de significado, al que los teóricos de la relevancia denominan "significado procedimental". El significado procedimental consiste en un conjunto de reglas computacionales acerca de cómo interpretar las proferencias. Estas reglas no sólo imponen restricciones sobre los contenidos explícitos de las proferencias, sino también sobre las asunciones contextuales presupuestas en el procesamiento de las proferencias y en las implicaciones interpretativas que las proferencias acarrean (Blakemore 2002, p. 185).

Entender las constantes lógicas como reglas no supone nada nuevo. "Los hipotéticos variables — sostiene Ramsey en 1929/2005 (p. 426)no son juicios sino reglas para juzgar. "Si me encuentro con un $\varphi$, debo considerarlo como un $\psi$ '." De manera similar, Ryle (1954/1969, p. 117) consideró las generalizaciones nomológicas, que tienen la estructura de los hipotéticos variables de Ramsey, como "un ticket inferencial (un ticket de temporada) que habilita a su poseedor [...] a pasar de una aseveración a otra, a ofrecer explicaciones de hechos dados y a realizar estados de cosas mediante la manipulación de lo que se encuentra como existiendo u ocurriendo". En el Tractatus 5.2341, 
Wittgenstein, por su parte, caracterizó la negación, la conjunción y la disyunción como operaciones.

El pragmatismo clásico, de Peirce en adelante, ha subrayado un contraste análogo al que existe entre conceptos y reglas en términos de premisas y principios de inferencia. Si la distinción no se hace, la conclusión de un argumento se alejará indefinidamente de las premisas. Esto es lo que, de acuerdo con Carroll (1895), la tortuga le mostró a Aquiles. Prior lo argumenta de la siguiente manera:

A veces - para volver a otra solución propuesta - se dice que una verdad lógica es aquella que no funciona en la inferencia como premisa a partir de la cual se extrae una conclusión, sino sólo como un principio de acuerdo con el cual la conclusión se extrae. Esta distinción es ciertamente importante; como Lewis Carroll lo ha mostrado, si no la hacemos no seremos capaces de encontrar premisas suficientes para ninguna inferencia. (Prior 1976, p. 125)

Con todo esto, podemos ahora ofrecer una demarcación preliminar entre marcadores, conectivas y constantes, por un lado, y el resto de las expresiones de nuestro lenguaje, por otro, atendiendo al tipo de ítem que codifican. Unas expresiones codifican conceptos, los ingredientes de las proposiciones, y otras codifican reglas que nos indican operaciones con conceptos y proposiciones. Las constantes de Begriffsschrift son reglas, las de Tarski (1966/1986) son términos que denotan entidades conjuntistas. Por esta razón, las constantes fregeanas encajan mejor con lo que hoy sabemos acerca del significado de estas expresiones en lenguaje natural que las constantes tarskianas.

No es mi pretensión comprometerme con ninguna teoría particular del significado. El objetivo de esta sección consiste simplemente en señalar que a la concepción de la lógica como la ciencia de la inferencia, la lógica-F, se le adapta perfectamente la concepción de las constantes lógicas como expresiones funcionales, cuyos argumentos son las entidades capaces de portar propiedades lógicas y de entrar en relaciones lógicas con otras entidades del tipo apropiado. Además, desde el punto de vista de sus significados, hay en la literatura contemporánea maneras de explicar cómo significan y qué función realizan sin tener que asumir la tesis descriptivista de que nombran entidades de ningún tipo.

\section{Una caracterización tentativa de las constantes lógicas}

Estamos ahora en posición de ofrecer una caracterización de constante lógica guiada por la comprensión de la lógica como la ciencia 
de la validez, o de la consecuencia lógica, en el sentido intuitivo habitual. ${ }^{7}$ La consecuencia lógica es la relación que se establece entre un grupo de proposiciones $P$, y una proposición $p$, cuando no es posible aseverar $P$ y rechazar $p$, so pena de contradicción (o de irracionalidad). La caracterización no será ad hoc, forzada para que se ajuste a una lista de constantes previamente aceptada; más bien recogerá lo que cabría esperar de la comprensión del objetivo de la lógica-F. Se explorará hasta dónde lleva el cambio de comprensión del objetivo de la lógica, el cambio que va de la verdad lógica a la validez y de las verdades lógicas a los principios de inferencia, cambios que se materializan en la lógica-F. Ya se han dado algunos pasos en secciones anteriores, cuyo contenido podemos resumir en lo siguiente: las constantes lógicas deben ser expresiones que admitan argumentos (expresiones predicativas de algún tipo) y deben representar reglas que nos permitan llevar a cabo los movimientos exigidos en una inferencia. Me propongo explicar de qué modo esta caracterización está conectada con la manera habitual de entender qué es la lógica. La conclusión a la que llegaré será, a grandes rasgos, que sólo unas cuantas expresiones destacadas como constantes lógicas en los cálculos estándar y no estándar son constantes lógicas genuinas. En concreto, de mi caracterización se seguirá que sólo algunos casos de negación, condicional y la combinación de condicional con cuantificadores binarios cumplen las condiciones para ser considerados constantes lógicas genuinas. Explicaré asimismo qué funciones realizan aquellas expresiones que, de acuerdo con mi caracterización, no tienen ese estatus. Una manera menos radical de defender lo mismo es decir que la lista habitual de las constantes lógicas no forma una clase homogénea desde el punto de vista de la función que los elementos de la lista realizan en las inferencias. En mi opinión, se alcanza un conocimiento más profundo de lo que es la lógica si se acepta que hay diferentes subconjuntos de expresiones lógicamente interesantes, todas ellas con funciones específicas que cumplir en nuestras prácticas inferenciales, en vez de intentar subsumir todas las expresiones que se han ido sumando a la lista de las constantes tradicionales bajo un único tratamiento.

${ }^{7}$ El "sentido intuitivo habitual" no es el que se deriva de la definición de Tarski de 1936. La interpretación de Tarski exige, para que un argumento sea válido, el que preserve la verdad en toda interpretación, manteniendo fijos ciertos términos, las constantes lógicas, que no identifica de manera independiente. Para una crítica de la definición modelo-teórica (y también de la sustitucional) de consecuencia, véase Etchemendy 1983 y 1990. 
En este contexto, propondré una aproximación general a las constantes lógicas que tenga en cuenta su estatus lógico-sintáctico, sus características semánticas y su función pragmática. Aunque considero lo que hacemos con palabras, con las palabras lógicas en este caso, como el punto de partida - y por eso considero esta propuesta como una aproximación pragmática al significado de las constantes lógicas-, eso no implica que los aspectos semántico y sintáctico deban pasarse por alto. Muy al contrario, el éxito de las tareas pragmáticas exige que las herramientas que los hablantes tienen a su disposición para llevarlas a cabo - y los oyentes a su disposición para entenderlas correctamente - posean las propiedades semánticas y estructurales apropiadas. Pero hay que tener en cuenta que es la función pragmática la que en último extremo determina qué es una constante lógica. Las propiedades semánticas y sintácticas constituyen sólo condiciones necesarias que delimitan conjuntos más amplios de expresiones.

La caracterización de constante lógica que propongo es [CL]:

[CL] Las constantes lógicas son predicables de orden superior, cuyos argumentos son predicables $n$-ádicos $(n \geq 0)$, esto es, conceptos y proposiciones. Su significado no consiste en la representación de entidades extralingüísticas de ningún tipo, ni conceptos ni objetos, sino que se determina a través de la función que realizan de marcar relaciones inferenciales entre conceptos y contenidos proposicionales.

[CL] implica una afirmación lógico-sintáctica — que las constantes lógicas son expresiones de orden superior-, una afirmación semántica -que las constantes lógicas ni nombran ni expresan conceptos-, y una afirmación pragmática — que al usarlas, los hablantes señalan la presencia de conexiones conceptuales preservadoras de la verdad-. Estos tres niveles, sintaxis, semántica y pragmática, deben verse como perspectivas distintas desde las que se mira a un mismo fenómeno, que como tal no presenta esta división. El fenómeno - nuestras prácticas inferenciales - es unitario; son nuestras conveniencias metodológicas las que aconsejan dividirlo de este modo. Ofrezco a continuación una explicación de los rasgos sintácticos, semánticos y pragmáticos que se exigen de las constantes lógicas.

4.1. Aspectos sintácticos de [CL]

[CL] exige que las constantes lógicas sean expresiones predicativas de orden superior, un rasgo lógico-sintáctico requerido por el aná- 
lisis de las relaciones lógicas como relaciones entre portadores de verdad potenciales. Los ítems conectados por relaciones lógicas pueden ser proposiciones completas (expresadas por predicables 0-ádicos) o conceptos $n$-ádicos $(n>0)$. La afirmación de una generalización nomológica, una ley de naturaleza, por ejemplo, nos permite hacer transiciones inferenciales entre conceptos, no sólo entre proposiciones completas. Si representamos la estructura de una generalización nomológica de la manera habitual, como un "hipotético variable" en la terminología de Ramsey,

(1) $\forall x(P x \rightarrow Q x)$,

la interpretación más natural de cuál es la información que transmiten las proferencias que representaríamos con la estructura (1) es, precisamente, la que Ramsey ofrece: que cuando vemos un $P$ tenemos que tomarlo como un $Q$. Si esto es así, lo que (1) representa es una transición inferencial segura (por el cuantificador universal) que permite aplicar el predicado del consecuente a aquello a lo que el predicado del antecedente se aplica. Junto a esto, las relaciones inferenciales pueden establecerse también entre proposiciones completas, como cuando decimos que de (1) se sigue (2),

(2) $\neg \exists x(P x \& \neg Q x)$.

En realidad, ni (1) ni (2) son proposiciones genuinas. Las proposiciones son entidades no lingüísticas ("interlingüísticas" las llama Sellars (1968, p. 100)) que se producen en el contexto de un acto de habla exitoso. (1) y (2) son meramente esqueletos de proposiciones que aquí se utilizan a modo de ilustración, teniendo en cuenta que estamos tratando los rasgos lógico-sintácticos de las constantes.

La parte sintáctica de [CL] ofrece asimismo una caracterización precisa de la intuición medieval de que las constantes lógicas son expresiones sincategoremáticas. La intuición medieval tiene una lectura sintáctica y una lectura semántica (véase Klima 2005). La lectura sintáctica responde a la idea de que las expresiones sincategoremáticas no pueden ser ni sujetos ni predicados y los predicables de orden superior en efecto no entran en ninguna de estas categorías. Por esa razón, Frege en Begriffsschrift abandonó el análisis de las proposiciones en términos de sujeto y predicado, precisamente para dar cabida a predicables de orden superior como los cuantificadores. También da expresión a la lectura sintáctica de la caracterización de las constantes lógicas como neutrales respecto del tema (topic-neutral), que Gilbert 
Ryle discute y rechaza en Ryle 1954/1969 (pp. 116 y ss.). El tema, podríamos decir, viene dado por las proposiciones, a cuyo contenido las constantes lógicas no contribuyen de ninguna manera. Esto último es una consecuencia de la caracterización semántica de las constantes que discuto a continuación.

\subsection{Aspectos semánticos de [CL]}

Desde un punto de vista semántico, [CL] afirma que las constantes lógicas ni nombran objetos ni representan conceptos, entendidos éstos como los ingredientes de las proposiciones. Dicho de modo más preciso, las constantes lógicas como expresiones no contribuyen con un componente conceptual a lo que se dice mediante las proferencias en las que aparecen. Hay otras expresiones que comparten con ellas este rasgo semántico, como el predicado de verdad, o los operadores modales, temporales y epistémicos. Este rasgo es lo que de una manera más vaga se recoge en la lectura semántica del tratamiento de las constantes como sincategoremata, a saber, que estas expresiones meramente cosignifican y que no pueden suponer el núcleo de significado ni del sujeto ni del predicado de las oraciones en las que aparecen. También recoge con precisión la intuición de la lectura semántica de la neutralidad temática, que Gómez-Torrente ha reformulado recientemente exigiendo que las constantes lógicas sean en cierto sentido "insustantivas" (Gómez-Torrente 2007, p. 183). Sincategoremicidad, neutralidad temática e insustantividad son formas alternativas de señalar el rasgo semántico que los filósofos del lenguaje y de la lógica han resaltado bajo el rótulo de "expresivismo", un rótulo que se aplica a la manera en la que significan las expresiones que no aportan ingredientes conceptuales identificables a la proposición. El expresivismo semántico ¿qué debe distinguirse del expresivismo de los términos éticos y del expresivismo de los informes en primera persona? es la posición que se defiende en el Tractatus y que ha vuelto a poner sobre la mesa Brandom para los casos del condicional y la negación, y para los términos semánticos (Brandom 1994, cap. 5). Los lingüistas, por su parte, hablan en este caso de "significado procedimental", una noción que no está aún del todo desarrollada y sobre la que hay un debate abierto, pero cuya propuesta teórica vino aconsejada por el mismo tipo de intuición semántica, a saber, la intuición de que significar no siempre es sinónimo de expresar un concepto o nombrar un objeto. El tratamiento expresivista, o la caracterización del significado de una expresión como procedimental, suele aplicarse a expresiones que desde un punto de vista lógico son de orden 
superior, esto es, a expresiones predicativas que tienen conceptos o proposiciones completas como argumentos. La razón debería ser obvia, pues mientras que las proposiciones clásicas todavía admiten una interpretación semántica descriptivista en los términos gramaticales de sujeto y predicado, y en los términos semánticos de nombrar y describir, en cuanto entran en juego expresiones $u$ operadores de orden superior la imagen clásica del lenguaje como instrumento para representar estados de cosas deja de ser intuitiva.

El término "expresivismo" produce un rechazo casi generalizado entre los lógicos y los filósofos de la lógica más clásicos. Hay una razón teórica para ello y es la creencia común de que las expresiones con significado expresivo no pueden intervenir en otras expresiones complejas que posean condiciones de verdad. La función de las expresiones con significado expresivo no sería describir estados de cosas sino dar visibilidad a sentimientos y emociones por parte del hablante. Ésta es la posición expresivista clásica, ligada al análisis de los términos éticos en el positivismo lógico (Ayer 1936, cap. 6, y Stevenson 1937, p. 21). El argumento tiene su origen en la versión fregeana del principio de composicionalidad: si en una expresión compleja uno de los términos carece de referencia, la expresión como un todo carece de valor de verdad (Frege 1892/1952, p. 65).

Sin embargo, parece obvio que expresiones con constantes lógicas pueden ser a su vez argumentos de constantes lógicas como ocurre cuando, por ejemplo, colocamos fórmulas complejas en el antecedente de un condicional. Además, las conectivas son, en la concepción estándar, "funciones de verdad", funciones cuyos argumentos y valores son valores de verdad, tal como se representa en las tablas de verdad. Ambas intuiciones juntas, el principio de composicionalidad y el comportamiento semántico de las expresiones en las que aparecen conectivas, parecen constituir una refutación de la posición expresivista. Esto es lo que se conoce como el argumento Frege-Geach $[\mathrm{AFG}]:^{8}$

[AFG] Si las expresiones con términos expresivos no tienen valor de verdad, no pueden caer bajo el alcance de funciones

\footnotetext{
${ }^{8}$ En realidad, lo que Geach 1960 defiende en su crítica al adscriptivismo es que las expresiones afectadas tendrían un comportamiento semántico diferente cuando aparecen aisladas y cuando aparecen bajo el alcance de una función de verdad. La versión recogida en $[\mathrm{AFG}]$ es una simplificación generalmente aceptada que preserva la idea original y que es suficiente para ilustrar la crítica a una interpretación expresivista de las constantes lógicas.
} 
de verdad. Y, sin embargo, se usan como argumentos de estas funciones sin que el resultado sea ningún tipo de sinsentido.

[AFG] se ha usado profusamente como refutación del expresivismo (véase por ejemplo Schroeder 2008, p. 704). Afortunadamente, no hay necesidad de aceptar la versión fregeana del principio de composicionalidad, que es lo que dispara la crítica que se recoge en [AFG]. La tesis expresivista respecto de las constantes lógicas que defendemos aquí es más débil que la requerida para poner en marcha el argumento. Ni el expresivismo ni la noción paralela de significado procedimental requieren que las expresiones sin significado conceptual destruyan el valor de verdad de los compuestos en los que aparecen. Nos detendremos por un momento en esta última idea. Consideremos las tres oraciones siguientes:

(3) Mi hijo es un gxfrrtl

(4) La Regenta no era feliz

(5) Madrid es la capital de España y la ciudad de México es la capital de los Estados Unidos Mexicanos.

La versión fregeana del principio de composicionalidad tiene como consecuencia el bloqueo del procesamiento de oraciones como (3) y (4). En la imagen clásica, el hablante obtiene la información codificada en la oración recuperando el significado de cada palabra (y tomando en consideración la estructura de la oración). Al finalizar el proceso se obtiene o bien una proposición o bien un valor de verdad, dependiendo de que apliquemos el principio de composicionalidad al sentido o a la referencia. Si en algún momento del proceso nos encontramos con un elemento que carece de valor semántico (sentido o referencia), el proceso se detiene y por tanto no se arrojan resultados acerca del valor semántico de la oración completa. En (3) hay una hilera de signos sin sentido, "gxfrrtl", por lo que la oración no expresaría ninguna proposición (y a fortiori no tendría valor de verdad). En (4) hay una expresión sin referencia, "La Regenta", por lo que la oración, aun expresando una proposición (un pensamiento, en Frege), carecería de valor de verdad.

Lo que defendemos en estas páginas respecto del significado de las constantes lógicas es que el principio de composicionalidad no tiene este efecto cuando se aplica a los compuestos con constantes lógicas. $\mathrm{Y}$ hay una buena razón para ello. El principio de composicionalidad se utiliza para obtener proposiciones (o sus valores de verdad). 
Cuando las constantes lógicas entran en escena, las proposiciones (o los valores de verdad) ya están disponibles. Esto es lo que significa que sean operadores de orden superior y que sean neutrales respecto del tema. En (3) y (4), las palabras sin sentido y sin referencia, respectivamente, debían aportar un componente para la determinación de la proposición expresada (o su valor de verdad). Cuando no lo hacen, el proceso se detiene. (3) no puede usarse para expresar una proposición, y (4), en la versión más clásica, no puede usarse para decir algo verdadero o falso. ¿Qué ocurre en (5) entonces? En (5), ninguna de las dos oraciones que son los argumentos de la conjunción, "Madrid es la capital de España" y "la ciudad de México es la capital de los Estados Unidos Mexicanos", presenta expresiones que carezcan de valor semántico. Por lo tanto, el proceso de obtención de las proposiciones expresadas por las dos oraciones puede seguir hasta el final. Una vez que las proposiciones están disponibles, se está en condiciones de analizar el papel de las constantes lógicas, de la conjunción en este caso. La tesis semántica que defendemos respecto de las constantes lógicas significa que las constantes no tienen como función aportar un concepto que entre en el proceso de composición de la proposición atómica al mismo nivel que los conceptos de primer orden que la componen. Las constantes lógicas entran en juego una vez que las proposiciones que son sus argumentos están disponibles, y el papel que desempeñan está relacionado con las posibilidades de interpretación de los compuestos y no con la representación de elementos de los estados de cosas. En el $\S 5$ de Begriffsschrift, Frege explica el significado del condicional del siguiente modo:

Si A y B significan contenidos juzgables, entonces hay las siguientes cuatro posibilidades

1) A es afirmada y B es afirmada;

2) A es afirmada y B es negada;

3) A es negada y B es afirmada;

4) A es negada y B es negada.

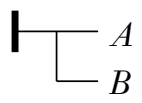

significa, pues, el juicio de que no tiene lugar la tercera de estas posibilidades, sino una de las otras tres. (Frege 1879/1972, p. 8) 
Una idea similar expresa Wittgenstein en el Tractatus, en 4.0621 y en 5.2341, entre otros aforismos.

La teoría expresivista clásica exige que la falta de referencia de una expresión sea infecciosa para toda expresión que la rodee. La tesis expresivista que se defiende en estas páginas, y que es la que se deduce de Begriffsschrift y la que se asume explícitamente en el Tractatus, no tiene esta exigencia: sólo afirma que el significado de estas expresiones no supone una contribución sustantiva a las condiciones de verdad de sus argumentos. Dicho de otro modo, que su papel semántico no consiste en colocar un concepto en la proposición, sin que eso signifique que no pueda formar parte de compuestos que expresen proposiciones genuinas.

Todas las constantes lógicas son términos expresivos desde un punto de vista semántico. Además, cada una de ellas debe codificar como su significado la función específica que realiza y que la hace ser la constante que es. [CL] no desciende a caracterizar el significado particular de cada constante, sino a caracterizar el tipo de expresión y en este sentido sólo puede incluir aquellos rasgos que sean comunes a la clase de las constantes lógicas. Queda un rasgo esencial: el componente dinámico. Pues si las constantes marcan movimientos inferenciales, entonces es razonable suponer que esta circunstancia debe recogerse de algún modo en su significado. Este rasgo pragmático se representa en el hecho de que las constantes lógicas deberían ser, explícita o implícitamente, operadores binarios.

\subsection{Aspectos pragmáticos de [CL]}

De acuerdo con [CL], la función pragmática de una constante lógica consiste en señalar el paso de un contenido a otro. Para nosotros, es la función pragmática de una expresión la que en último extremo determina si es o no una constante lógica. Meramente señalando características sintácticas y semánticas no se delimita la clase de las constantes lógicas. Como nos muestra la historia de los diversos intentos de definición desde la época medieval hasta nuestro días, ni todas las expresiones sincategoremáticas o insustantivas son lógicamente relevantes, ni lo son todas las expresiones de orden superior o con significado expresivo. Las constantes lógicas son constantes lógicas porque los agentes las usan para marcar relaciones lógicas, i.e., relaciones inferenciales.

Colocar la atención en el uso de las expresiones por parte de los hablantes conlleva desplazar la caracterización desde los tipos de expresiones a sus ejemplares. Ejemplares del mismo tipo pueden usarse 
con propósitos distintos. Sólo aquellos ejemplares de expresiones que se usen para marcar inferencias contarán, conforme a la perspectiva que defendemos aquí, como constantes lógicas.

En los manuales se suele explicar que las constantes lógicas marcan los nudos de las estructuras válidas (Haack 1978, p. 23, GómezTorrente 2007, pp. 180-181), se ha llegado incluso a sostener que las constantes funcionan como signos de puntuación (Dosen 1989), una idea que también aparece en el Tractatus, 5. 4611. Ambas afirmaciones son discutibles, pero comparten la intuición correcta de que las constantes aparecen en el discurso colocadas entre los ítems entre los que se establecen las relaciones de inferencia. Peirce sostuvo que "no hay sino una relación lógica primaria y fundamental, la de inferencia, expresada por ergo" $(1932,3.440)$.

De la lista de las constantes lógicas habituales, el condicional es el que más naturalmente representa la conexión con la práctica de hacer inferencias. Muy diversos autores han defendido la intuición de que los condicionales codifican inferencias. Esta intuición va acompañada de la asunción generalizada de que el condicional y, desde una perspectiva metateórica, la implicación constituyen nuestras herramientas lógicas básicas. Implicación, condicional e inferencia son aspectos de la misma realidad. La implicación es la relación que se da entre las premisas y la conclusión de un argumento válido. Desde Begriffsschrift, la representamos como " $\vdash$ " y, tras el desarrollo de la semántica formal, como " $\models$ " y la expresamos en español con expresiones como "asî", "luego", "por lo tanto", y otras. El teorema de deducción de la lógica de primer orden muestra que una inferencia válida puede representarse como la validez del correspondiente condicional material. Sea $\Gamma$ el conjunto de las formulas $\left\{\gamma_{1}, \gamma_{2}, \ldots\right.$, $\left.\gamma_{n}\right\}$, el teorema de deducción dice que si una fórmula $\delta$ se sigue de un conjunto de fórmulas $\Gamma$, entonces el condicional que tiene la conjunción de las formulas en $\Gamma$, i.e. $\left(\gamma_{1}, \gamma_{2}, \ldots, \gamma_{n}\right)$, como su antecedente, y la formula $\delta$ como su consecuente es válido:

$$
\text { [TD]: Si } \Gamma \vdash \delta \text {, entonces } \vdash\left(\gamma_{1}, \gamma_{2}, \ldots, \gamma_{n}\right) \rightarrow \delta \text {. }
$$

La intuición codificada por [TD] está presente en los más diversos tratamientos del condicional. Peirce, por ejemplo, declaró que "si una proposición hipotética es verdadera, tanto si lo sabemos como si no [...], la inferencia del antecedente al consecuente es válida. Pero que sea lógicamente válida es otra cosa muy distinta" (Peirce 1932, p. 332). Desde la lingüística se acepta una interpretación similar: 
Los condicionales son paradigmáticos por sus mensajes independientes no afirmados. Disfrutan también de un abanico bien publicitado de logros deductivos [...]. Esto es porque son argumentos condensados, por supuesto. Afirmar uno es recurrir al argumento mientras retiramos el compromiso con una premisa. (Dudman 1991, p. 228)

La validez de [TD] es un argumento en favor de la tesis pragmática, defendida en los últimos años por Brandom, de que usamos los condicionales para hacer explícitas conexiones inferenciales entre conceptos desde el punto de vista del hablante. Para explicar la diferencia entre lo que tradicionalmente se han considerado entimemas y los argumentos lógicamente válidos, Brandom escribe:

Ha resultado ser una estrategia útil considerar que las inferencias aparentemente entimemáticas están bien tal como están, y tratar los condicionales no como premisas suprimidas sino como si hicieran explícito (al expresar en la forma de una afirmación) lo que está implícito en la aceptación de inferencias. Parte de lo que se gana al considerar las cosas de esta manera es la comprensión del papel expresivo que desempeñan los condicionales; éstos se entienden como el hacer proposicionalmente explícitos (= aseverables) los compromisos inferenciales. (Brandom 1994, p. 247)

La manera de entender los condicionales representada por este texto y, para lectores menos inclinados pragmáticamente, por [TD] permite que, para mis propósitos, no tengamos que prestar mucha atención a la distinción entre uso y mención, ni a la de lenguaje objeto y metalenguaje. Estas distinciones pueden mantenerse estrictamente para lenguajes artificiales, pero en el lenguaje natural pierden parte de su sentido. Lo que es informativo, sin embargo, es que desde muy diversas perspectivas se asuma que el condicional es un modo, o quizá el modo, de codificar inferencias. Si esto es así, el condicional cumpliría con los criterios recogidos en [CL] para ser una constante lógica: (i) sintácticamente, admite proposiciones y conceptos como sus argumentos, (ii) semánticamente, expresa una regla pero ni nombra objetos ni representa conceptos, y (iii) pragmáticamente, lo usamos para hacer manifiesta una inferencia.

Y ahora podemos preguntarnos: ¿qué otras expresiones acompañarán al condicional en la lista de constantes lógicas genuinas? Antes de pasar a revisar los posibles candidatos, recordemos que autores de mucho peso, como Peirce (en el fragmento citado en la página anterior), han considerado que la implicación era la única expresión 
merecedora de tal distinción. En el siglo XX, Prior expresó una opinión ligeramente menos radical:

\begin{abstract}
Podríamos, sin embargo, encontrar aquí una sugerencia para un criterio mejor, un criterio que Peirce usó en la práctica. Hasta donde puedo ver, una verdad que se usa como un principio de inferencia debe ser una implicación universal — debe ser esto para poder funcionar de algún modo como una regla-. Universalidad e implicación son, por lo tanto, comunes a todos los principios de inferencia, independientemente de que sean "materiales" o "no lógicos"; así podemos definir las verdades lógicas como aquellas en cuya formulación todos los signos ocurren vacuamente excepto los signos de universalidad e implicación; "no es el caso de que $p$ " significa "Si $p$ entonces cualquier cosa". La totalidad de las funciones de verdad se puede desarrollar en términos de implicación y negación; y con la universalidad y la negación tenemos toda la teoría de la cuantificación. (Prior 1976, p. 127)
\end{abstract}

Para Prior, son el condicional y la generalidad las nociones lógicas básicas, la negación se deriva de estas dos. Brandom considera el condicional y la negación como los recursos básicos (véase, por ejemplo, Brandom 1994, p. xix). Veamos qué se sigue de [CL].

\title{
5. ¿Qué se sigue de [CL] para los candidatos habituales?
}

La intuición pragmática general de que para comprender qué es una constante lógica debemos comenzar con el análisis de los propósitos de los hablantes al usarlas ha guiado nuestro argumento en las páginas previas. Cuando estamos inmersos en la práctica de inferir, los hablantes usamos expresiones específicas para indicar dónde están los puntos de transición de unos contenidos que en principio aceptamos a otros contenidos que asumimos que se siguen de ellos. Como se ha defendido en secciones anteriores, la conexión inferencial básica es la de implicación, que se representa igualmente haciendo uso del condicional.

El propósito de esta última sección será aplicar [CL] a la lista de expresiones que con mayor frecuencia se han considerado constantes lógicas y ver cómo se comportan. También explicaremos qué funciones realizan aquellas expresiones que de acuerdo con [CL] no alcancen el estatus de constante lógica genuina. La tesis que estamos defendiendo admite una formulación más débil, como se ha indicado ya: que la lista de las constantes lógicas habituales no forma una clase natural. Dentro de la lista pueden distinguirse subgrupos bien diferenciados con funciones distinguibles. 
[CL] reúne tres aspectos individualmente necesarios y conjuntamente suficientes. Manteniendo algunos de estos aspectos y dejando en suspenso otros se obtienen conjuntos cada vez más amplios de expresiones relacionadas de modos diversos con la práctica de inferir y en cuanto a sus significados más o menos similares a las constantes lógicas genuinas, i.e., las que cumplen todos los requisitos de [CL].

\section{Cuadro 1}

\begin{tabular}{|l|l|l|}
\hline \multicolumn{1}{|c|}{ Monarios } & \multicolumn{1}{c|}{ Binarios } \\
\hline $\begin{array}{l}\text { Predicables de } \\
\text { orden } n+1\end{array}$ & $\begin{array}{l}\text { negación, cuantificador existen- } \\
\text { cial, operadores modales, tempo- } \\
\text { rales y epistémicos }\end{array}$ & $\begin{array}{l}\text { condicional, conjunción, disyunción, } \\
\text { bicondicional, cuantificador universal } \\
\text { (+ condicional), cuantificadores no- } \\
\text { estándar (+ condicional) }\end{array}$ \\
\hline $\begin{array}{l}\text { Significado } \\
\text { expresivo }\end{array}$ & $\begin{array}{l}\text { negación, cuantificador existen- } \\
\text { cial, operadores modales, tempo- } \\
\text { rales y epistémicos }\end{array}$ & $\begin{array}{l}\text { condicional, bicondicional, cuantifica- } \\
\text { dor universal (+ condicional), cuantifi- } \\
\text { cadores no-estándar (+ condicional) }\end{array}$ \\
\hline $\begin{array}{l}\text { Marcadores } \\
\text { inferenciales }\end{array}$ & $\begin{array}{l}\text { (negación* } \\
\text { (n) }\end{array}$ & $\begin{array}{l}\text { condicional, bicondicional, cuantifica- } \\
\text { dor universal (+ condicional }{ }^{\star} \text { ), cuanti- } \\
\text { ficadores no-estándar (+ condicional }\end{array}$ \\
\hline
\end{tabular}

Nota. Las expresiones marcadas con "*”" suscitan debates acerca de su inclusión como constantes y bajo qué forma.

El cuadro 1 representa la clasificación de la lista de expresiones atendiendo a sus rasgos de significado, pero esta clasificación no pretende ser a priori. Tiene que haber razones independientes de [CL] que justifiquen la inclusión de cada tipo de expresión en la casilla correspondiente. En lo que sigue ofreceremos estas razones, aunque sólo sea de manera genérica.

En el cuadro 1 no aparecen ni predicados y relaciones de primer orden, ni tampoco objetos. Las teorías invariantistas consideran que las constantes lógicas son objetos del tipo más abstracto (véase Tarski 1966/1986, p. 149); entre ellos cuentan a la clase universal y 
la clase vacía, la identidad y la diferencia. La crítica que hacemos a las aproximaciones invariantistas se resume en que, mientras que en ellas se ve con claridad que estos objetos son constantes, es difícil entender en qué sentido son lógicos (en el contexto de la lógica FP), esto es, cuál es su contribución a la realización y la expresión de inferencias. Como relaciones de primer orden, la identidad y la pertenencia tampoco aparecen en el cuadro 1. Las relaciones inferenciales se establecen entre portadores (potenciales) de verdad, i.e., conceptos y proposiciones, y no entre objetos. La pertenencia dejó de ser considerada una constante lógica de manera generalizada con el ocaso del logicismo. En la actualidad son muchos los autores que no incluyen la identidad en la lista de sus propuestas. ${ }^{9}$

Las expresiones que [CL] identifica como constantes lógicas están en la última fila del cuadro. Todas ellas tienen casos que funcionan como marcadores inferenciales, y cumplen además con los requisitos semántico y sintáctico. Están dividas en dos tipos: las que son operadores monarios y las que poseen dos argumentos. La negación es, a mi entender, el único operador monario con derecho a estar en la fila de los marcadores inferenciales, aunque su inclusión o no en la lista final de las constantes genuinas abre un debate sustantivo. Los términos del debate son los siguientes: si las constantes lógicas marcan transiciones inferenciales y, como he defendido, los rasgos semánticos y sintácticos están al servicio de la función pragmática, sería de esperar que las constantes lógicas genuinas fueran relatores binarios de orden superior. Pero la negación es un operador monario, por lo que debería correr la misma suerte que otros operadores monarios, como los operadores modales, temporales o epistémicos. Recuérdese que Peirce no contempla el caso de la negación y que Prior la considera definible en términos de generalidad y condicional. Brandom, por el contrario, sí lo hace. No ofreceré una respuesta definitiva. me mantengo fiel a la idea de que [CL] no es una propuesta ad hoc, y a mi compromiso de aceptar lo que se derive de [CL] tomando en consideración argumentos independientes acerca del significado de las expresiones.

Sin embargo, creo que hay razones para no eliminar por completo de la lista ciertos usos de la negación. La negación en los lenguajes naturales es una herramienta sofisticada. Puede servir como formador de predicables complejos, como cuando formamos "infeliz" a partir de "feliz". La diferente composición de las proposiciones expresadas mediante las dos oraciones (a) y (b),

${ }^{9}$ Véanse, por ejemplo, Peacocke 1976, pp. 234 y 237, y Warmbrõd 1999, p. 521. 

a. Joan es feliz,
b. Joan es infeliz

puede representarse por medio de la negación como

$$
\begin{aligned}
& \text { (a.1) } P a \\
& \text { (b.1) } \neg P a
\end{aligned}
$$

En este uso, su función es meramente combinatoria. Nos permite construir predicables negativos complejos a partir de otros más simples que no involucran la negación. Y en este uso, no diríamos que la negación es una constante lógica.

La negación puede servir también para invertir el "sentido" de una proposición completa. Ésa es la sugerencia del Tractatus y es lo que representamos con su tabla de verdad. Wittgenstein escribe en 4.0621 que "las proposiciones ' $p$ ' y ' $\sim p$ ' tienen sentido opuesto, pero les corresponde una y la misma realidad", y en 5.2341 "El sentido de una función de verdad de $p$ es una función del sentido de $p$. Negación, adición lógica, multiplicación lógica, etc., etc., son operaciones. (La negación invierte el sentido de una proposición)". En este uso, la negación tampoco cuenta como una constante lógica de acuerdo con [CL].

Sin embargo, hay aún otro uso de la negación que podría ofrecer indicios para su consideración como constante lógica. Con la negación, podemos negar, rechazar o bloquear una transición inferencial. Supongamos que alguien declara (c),

c. Todos los políticos son deshonestos.

(c) incorpora la idea de que la aplicación del concepto "ser un político" a un objeto nos habilita a deducir de él que es deshonesto. Esto es lo que justifica el que traduzcamos las oraciones universales afirmativas como condicionales cuantificados. Decimos así que la forma lógica estándar de (c) es (c.1),

$$
\text { (c.1) } \forall x(P x \rightarrow D x) \text {. }
$$

La negación de (c),

(c.3) No todos los políticos son deshonestos, 
supone el bloqueo de la transición desde " $x$ es un político" a " $x$ es deshonesto". En este uso, la negación supone la operación contraria a la representada por el condicional. El bloqueo de una transición, como la transición misma, requiere dos argumentos. $\mathrm{Y}$ en este sentido, aunque sintácticamente decimos que la negación afecta a (c) como un todo, teniendo así una única proposición como argumento, desde un punto de vista pragmático lo que se niega es el paso de antecedente a consecuente, y así estamos también aquí ante un movimiento, un bloqueo en este caso, de un concepto a otro. En este uso, hay razones para incluir la negación entre las constantes.

La relación entre incompatibilidad conceptual y negación, que da apoyo a la interpretación de algunos usos de la negación como una operación binaria, se ha defendido desde perspectivas diversas. J.L. Bermúdez, por ejemplo, analizando la racionalidad de los animales, escribe:

El primer tipo de razonamiento puede describirse como razonamiento a partir de una alternativa excluyente. Es el tipo de inferencia que lleva a una criatura desde el reconocimiento de que uno de un par de estados de cosas incompatibles ocurre hasta el reconocimiento de que el otro no ocurre. [...] Es natural formalizarlo en el cálculo proposicional como un caso de silogismo disyuntivo (la transición de "A o B" y "no A" a "B", donde "A" representa "La gacela no está en el abrevadero" y "B", "El león no está en el abrevadero"). (Bermúdez 2006, p. 129)

La incompatibilidad conceptual o proposicional, que permite pasar de la constatación de que se da una situación a la conclusión de que otra situación incompatible no puede darse, es un mecanismo inferencial básico que se representa en los lenguajes naturales y artificiales a través de la negación. Cuando la negación indica incompatibilidad es, desde un punto de vista semántico, un operador binario. En este uso que subyace al silogismo disyuntivo es una constante lógica.

Hemos visto que el condicional, en muchos de sus usos, se comporta claramente como una constante lógica. Hemos argumentado que la negación suscita debate, aunque he ofrecido razones para apoyar la inclusión de algunos de sus usos en la lista de las constantes lógicas. Veremos ahora un caso de constante lógica tradicional que no es una constante lógica genuina de acuerdo con [CL]: la conjunción. La conjunción es un relator de orden superior, pero no tiene como función marcar ninguna transición inferencial. Los ítems ligados mediante una conjunción no guardan (o no tienen por qué guardar) ninguna relación inferencial entre ellos. La proposición conjuntiva como un 
todo está, naturalmente, en relaciones inferenciales con otras proposiciones, con ambos conyuntos por ejemplo, pero la conjunción como tal no tiene la función de indicar que estos conyuntos estén relacionados de ningún modo. Así, la conjunción no cumple el requisito pragmático para ser una constante.

La conjunción, tanto en los lenguajes naturales como en los lenguajes artificiales, cumple una obvia función sintáctica: puede servir para construir predicables conjuntivos a partir de predicables más simples, y fórmulas conjuntivas a partir de fórmulas más simples. Los ejemplos (d) y (e) sirven para ilustrar estos usos,

d. Hay políticos honestos,

e. Mary sacó la llave y Juan abrió la puerta.

Esta función es imprescindible para convertir complejos de predicables y proposiciones individuales en unidades sintácticas capaces de saturar el lugar de argumento de algún operador de orden superior. En el ejemplo (d), lo que tenemos son dos predicables "ser político" $(P x)$ y "ser honesto" $(Q x)$ y un predicable de segundo orden monario, "Hay". El cuantificador existencial en la interpretación clásica fregeana no es más que la negación del número cero y, como el resto de las expresiones numéricas y de cantidad, indica el tamaño de la extensión de un concepto (véase Frege 1884/1980, § 53). El tamaño es una propiedad de un concepto, sea este simple o complejo, y si lo que queremos expresar es que la extensión que tienen en común los conceptos "ser político" y "ser honesto" no es vacía, hay que construir el predicable conjuntivo (d.1),

(d.1) $P x \& Q x$,

que es monario (por la repetición de la variable), y que podríamos representar sin pérdida de información como (d.2),

$$
\text { (d.2) }(P \& Q) x \text {. }
$$

De este predicable, (d) dice que no es vacío, y lo representamos haciendo de (d.1) o (d.2) el argumento de un predicable de existencia de segundo orden, (d.3),

$$
\text { (d.3) } \exists x(P x \& Q x) \text {. }
$$


Con ejemplos como (e), que no indican composición de predicables, la función de la conjunción es similar. Podríamos querer hacer de (e) el argumento de otro operador de orden superior. (e) une dos oraciones, "Mary sacó la llave" y "Juan abrió la puerta". Si necesitamos que la información de esas dos oraciones sea conjuntamente el antecedente de un condicional, como en (e.1),

(e.1) Si Mary sacó la llave y Juan abrió la puerta, entonces no la derribaron a patadas,

tenemos que componer las dos oraciones como una unidad sintáctica y para eso usamos la conjunción. La pragmática contemporánea añade a esta interpretación sintáctica la interpretación cognitiva de que los hablantes, mediante el uso de la conjunción, transmiten la información de que los contenidos conjuntados han de ser procesados como una unidad y que la unidad es la que posee el valor cognitivo óptimo. Si la interpretación de la conjunción es ésta de la unidad de procesamiento, se añade otra razón, esta vez desde la lingüística, a la tesis de que la conjunción no sirve para mostrar una transición inferencial. Carston, por ejemplo, dice:

La observación de que la conjunción-“y” comprende una única unidad de procesamiento cumple un papel esencial; el otro componente de la explicación tiene que ver con el hecho de que la relación de consecuencia lógica es una [relación] inferencial y las relaciones inferenciales $[\ldots]$ se dan entre unidades de procesamiento distintas. Se sigue que una unidad de conjunción puede funcionar, como un todo, como una premisa en un argumento, o, como un todo, como una conclusión en un argumento, pero que no puede comunicar que se da una relación premisa-conclusión entre sus proposiciones constituyentes. (Carston 2002, p. 263)

Carston también defiende que la conjunción puede tener algún tipo de significado conceptual, esto es, que puede contribuir con un ingrediente conceptual a lo que se dice (véase Carston 2002, cap. 3). Tampoco cumpliría pues el requisito semántico de poseer significado meramente expresivo.

Volvamos al cuadro 1. En la última fila, los operadores binarios que aparecen son el condicional y la combinación de éste con diversos cuantificadores, estándar y no estándar. A principios del siglo XX, era habitual distinguir entre enunciados hipotéticos y enunciados hipotéticos variables, siendo estos últimos enunciados cuantificados (con variables aparentes, se decía; véase Ramsey 1929/2005, p. 421). Esta 
práctica es razonable, y algunos filósofos de la lógica posteriores la han seguido. Barwise (1989, p. 100) distingue entre condicionales no cuantificados y condicionales cuantificados y considera que estos últimos son más básicos ya que los condicionales no cuantificados adquieren sus significados a partir de aquéllos, de los que son casos. Ante las expresiones en la casilla inferior derecha del cuadro 1 pueden tomarse dos opciones: (A) que el condicional, por un lado, y las combinaciones de condicionales-con-cuantificadores (como se representan en los cálculos clásicos), por otro, son constantes lógicas distintas, o bien (B) que tenemos condicionales, que son constantes lógicas, y luego cuantificadores de diversos tipos que también son constantes lógicas. (B) se ajusta más a la práctica en los cálculos, y (A) se ajusta más a lo que vemos en el lenguaje natural, donde decimos cosas como (f), (g) y (h),

f. Todos los mexicanos son simpáticos,

g. Muchos españoles comen ajo,

h. Pocos estadounidenses aprecian el chile,

sin que a simple vista haya ningún condicional funcionando independientemente del cuantificador. La interpretación del conjunto de operadores binarios de la última fila del cuadro 1 puede dejarse también como una cuestión abierta.

Una pregunta que habitualmente se plantea cuando se dejan fuera de la lista de constantes lógicas algunos candidatos aparentemente claros, como ocurre con [CL] y la conjunción, es cómo puede ocurrir esto teniendo en cuenta que diversos conjuntos de constantes lógicas son interdefinibles. Estamos acostumbrados a distinguir en la lógica de primer orden conjuntos adecuados de conectivas, como la negación y la conjunción, la negación y el condicional o la negación y la disyunción. Estos conjuntos permiten definir todas las funciones de verdad. ¿No significaría esta interdefinibilidad que las expresiones así conectadas son del mismo tipo, esto es, que si unas son constantes lógicas las demás también deben serlo? La respuesta es negativa. Las expresiones que son las contrapartidas en lenguaje natural de las constantes de los cálculos no son interdefinibles. El papel que desempeña el condicional no es el de la conjunción, ni el de la disyunción es el de la conjunción. La interdefinibilidad de las constantes de los cálculos de primer orden sólo significa que la parte del significado que se deja representar en las tablas de verdad de las conectivas, o en los modelos mediante los que se interpretan las fórmulas de los 
cálculos, es demasiado pobre para dar cuenta de las diferencias entre ellas. Únicamente atendiendo a los aspectos pragmáticos del significado podemos dar cuenta de la riqueza de las expresiones del lenguaje natural que cumplen un papel relevante en las prácticas inferenciales.

\section{A modo de conclusión (provisional)}

Ahora es el momento de resumir las tesis que he defendido y ofrecer algunas ideas a modo de conclusión. He querido analizar el problema de las constantes lógicas centrándome en dos cuestiones más básicas: la primera, qué entendemos por lógica. Me he incorporado a la tradición lógica que, comenzando con Peirce y Frege, ha derivado a través de Gentzen en las aproximaciones naturales a la inferencia: la lógica es la ciencia de la validez. La segunda cuestión que he perseguido es qué rasgos lógicamente relevantes poseen las expresiones de lenguaje natural que son las contrapartidas de las constantes de los cálculos. He aceptado la tesis pragmática de que la misma expresión tipo puede usarse para funciones diversas, y he defendido que ser una constante lógica es una propiedad de ejemplares de expresiones. Para ello, hemos tenido en cuenta lo que hacen los lingüistas y filósofos del lenguaje. El resultado tentativo ha sido la caracterización [CL]. De acuerdo con ella, los condicionales y los condicionales cuantificados (en diversas interpretaciones) se ajustan claramente a la propuesta. La negación presenta algunas cuestiones debatibles, aunque nos inclinemos a aceptar algunos de sus usos como constantes genuinas. El resto de los operadores en el cuadro 1 no son constantes lógicas genuinas, o al menos no son las básicas, en la versión más débil de mi tesis. Los operadores modales, epistémicos y temporales funcionan como operadores de cambio de circunstancia pero no expresan relaciones inferenciales entre contenidos. Las lógicas modales, temporales y epistémicas son lógicas porque incorporan constantes lógicas genuinas y tienen como propósito analizar las relaciones inferenciales en un ámbito particular del discurso, sin que esto obligue a que todas las expresiones que en esos cálculos se mantienen constantes tengan que ser sólo por ello constantes lógicas. ${ }^{10}$

\footnotetext{
${ }^{10}$ Quiero expresar mi agradecimiento a Gabriel Sandu y a Susan Haack, por innumerables horas de fructífero debate en mis estancias en Helsinki y Miami, en 2004 y 2005, respectivamente. A Raymundo Morado, por sus sugerencias y críticas constructivas durante muchos años de encuentros en congresos y workshops. A mis antiguos alumnos y becarios, y ahora colegas, Martin Andor, Stavros Assimakopoulos y Arancha San Ginés por sus atinados e iluminadores comentarios a anteriores versiones de este trabajo. Muchas de las ideas de trasfondo que aquí se asumen
} 


\section{BIBLIOGRAFÍA}

Ayer, A., 1936 (1946), Language, Truth and Logic, 2a. ed., Gollancz, Londres.

Barwise, J., 1989, The Situation in Logic, Center for the Study of Language and Information, Stanford.

Bermúdez, J.L., 2006, “Animal Reasoning and Proto-Logic", en S. Hurley y M. Nudds (comps.), Rational Animals?, Oxford University Press, Oxford, pp. 127-137.

Blakemore, D., 2002, Relevance and Linguistic Meaning. The Semantics and Pragmatics of Discourse Markers, Cambridge University Press, Cambridge (Cambridge Studies in Linguistics, 99).

, 2000, "Procedures and Indicators: 'Nevertheless' and 'but'", Journal of Linguistics, vol. 36, no. 3, pp. 463-486.

, 1992, Understanding Utterances, Blackwell, Oxford.

, 1989, "Denial and Contrast: A Relevance Theoretic Analysis of 'But'", Linguistics and Philosophy, vol. 12, pp. 15-37.

, 1988, "So' as a Constraint on Relevance”, en R. Kempson (comp.), Mental Representations: The Interface between Language and Reality, Cambridge University Press, Cambridge, pp. 183-195.

- 1987, Semantic Constraints on Relevance, Basil Blackwell, Oxford. Blakemore, D. y R. Carston, 2005, "The Pragmatic of Sentential Coordination with and*", Lingua, vol. 116, no. 4, pp. 569-589.

Brandom, R., 2008, Between Saying and Doing. Towards an Analytic Pragmatism, Oxford University Press, Oxford.

— 2000/2002, Articulating Reasons. An Introduction to Inferentialism, Harvard University Press, Cambridge, Mass./Londres. [Versión en castellano: La articulación de las razones: una introducción al inferencialismo, trad. E. de Bustos y E. Pérez Sedeño, Siglo XXI, Madrid, 2002.]

\section{— - 1994, Making It Explicit. Reasoning, Representing, and Discursive Commitment, Harvard University Press, Cambridge, Mass.}

han ido tomando forma en mi mente gracias al trabajo en colaboración que vengo realizando con mi colega Neftalí Villanueva, al que estoy profundamente agradecida. A los alumnos del Posgrado de Lógica y Filosofía de la Ciencia, que han asistido al desarrollo de mis posiciones sobre filosofía de la lógica con entusiasmo, les debo la decisión de expresar mis puntos de vista en un formato publicable y la energía para llevar esa decisión a término. También agradezco a dos árbitros anónimos de la revista Crítica sus valiosas sugerencias, que me han permitido reescribir y mejorar tanto mi comprensión de los asuntos debatidos como mi exposición. Este trabajo ha sido posible gracias a la financiación recibida para dos proyectos de investigación de los que soy IP, "Naturalismo y Pragmatismo Contemporáneos" HUM4099, financiado por la Consejería de Innovación de la Junta de Andalucía, y "Conceptos de Orden Superior" FFI2010-15704, financiado por el Ministerio de Ciencia e Innovación del Gobierno de España. 
Carroll, L., 1895, "What Achilles Said to the Tortoise", Mind, vol. 15, pp. 279-280.

Carston, R., 2002, Thoughts and Utterances. The Pragmatics of Explicit Communication, Blackwell, Oxford.

—_, 1993, "Conjunction, Explanation and Relevance", Lingua, vol. 90, pp. $27-48$.

Dosen, K., 1989, "Logical Constants as Punctuation Marks", Notre Dame Journal of Formal Logic, vol. 30, no. 3, pp. 362-381.

Dudman, V.H., 1991, "Interpretations of "if'-Sentences", en F. Jackson, Conditionals, Oxford University Press, Oxford, 1991, pp. 202-232.

Dummett, M., 1991, The Logical Basis of Metaphysics, Harvard University Press, Cambridge, Mass.

- 1977, Elements of Intuitionism, Oxford University Press, Oxford (Oxford Logic Guides).

Engel, P., 2006, "Logic, Reasoning and the Logical Constants", Croatian Journal of Philosophy, vol. 6, no. 17, pp. 219-285.

Etchemendy, J., 1990, The Concept of Logical Consequence, Harvard University Press, Cambridge, Mass./Londres.

— , 1983, "The Doctrine of Logic as Form", Linguistic and Philosophy, vol. 6, pp. 319-334.

Frápolli, M.J. (comp.), 2007, Filosofía de la lógica, Tecnos, Madrid.

Frege, G., 1979, Posthumous Writings, Basil Blackwell, Oxford.

—_, 1918-1919/1974, "El pensamiento. Una investigación lógica”, Escritos lógico-semánticos, trad. C.R. Luis y C. Pereda, Tecnos, Madrid, pp. 136157.

— 1892/1952, "On Concept and Object", en P. Geach y M. Black (comps.), Translations from the Philosophical Writings of Gottlob Frege, Basil Blackwell, Oxford.

— 1884/1980, The Foundations of Arithmetic, Basil Blackwell, Oxford. -, 1879/1972, Conceptografía: los fundamentos de la aritmética. Otros estudios filosóficos, trad. Hugo Padilla, Instituto de Investigaciones Filosóficas-UnAM, México.

Geach, P., 1969, "Ascriptivism", The Philosophical Review, vol. 69, pp. 221-225.

- 1960, Reference and Generality. An Examination of Some Medieval and Modern Theories, Cornell University Press, Ithaca/Londres.

Gentzen, G., 1969, Collected Papers, North-Holland, Ámsterdam.

—_, 1935, "Untersuchungen über das logische Schliessen" ("Investigations into Logical Deduction"), Mathematische Zeitschrift, vol. 39, pp. 176210, 405-431.

Goldfarb, W., 1979, "Logic in the Twenties. The Nature of Quantifiers", Journal of Symbolic Logic, vol. 44, pp. 351-368.

Gómez-Torrente, M., 2011, "Constante lógica", en Vega y Olmos 2011, pp. 129-134.

—_, 2007, “Constantes lógicas”, en Frápolli 2007, pp. 179-205. 
Gómez-Torrente, M., 2002, "The Problem of Logical Constants", Bulletin of Symbolic Logic, vol. 8, pp. 1-37.

Grice, H.P., 1989, Studies in the Way of Words, Harvard University Press, Cambridge, Mass.

— , 1981, "Presupposition and Conversational Implicature", en P. Cole (comp.), Radical Pragmatics, Academic Press, Nueva York, pp. 183197.

— 1975, "Logic and Conversation”, en P. Cole y J.L. Morgan (comps.), Syntax and Semantics, vol. 3, Speech Acts, Academic Press, Nueva York, pp. 41-58.

Haack, S., 1978, Philosophy of Logics, Cambridge University Press, Cambridge.

Haaparanta, L. (comp.), 2009, The Development of Modern Logic, Oxford University Press, Oxford.

Hacking, I., 1979, "What Is Logic?", Journal of Philosophy, vol. 76, pp. 285-319.

Hall, A., 2007, "Do Discourse Connectives Encode Concepts or Procedures?", Lingua, vol. 117, no. 1, pp. 149-174.

Higginbotham, J., 2000, "On Second-Order Logic and Natural Language", en G. Sher y R. Tieszen (comps.), Between Logic and Intuitionism. Essays in Honor of Charles Parsons, Cambridge University Press, Cambridge, pp. 79-99

Hintikka, J., 1997, “No Scope for Scope?”, Linguistics and Philosophy, vol. 20 no. 5 , pp. $515-544$.

Hintikka, J. y G. Sandu, 2007, “¿Qué es la lógica?”, en Frápolli 2007, pp. 15-54.

Klima, G., 2005, "Syncategoremata", Elsevier's Encyclopedia of Language and Linguistic, 2a. ed., ed. Keith Brown, Elsevier, Oxford, vol. 12, pp. 353-356.

Kneale, W. y M. Kneale, 1962, The Development of Logic, Clarendon Press, Oxford.

Mellor. D.H., 1978, Foundations: Essays in Philosophy, Logic, Mathematics, and Economics, Routledge and Kegan Paul, Londres.

Nepomuceno, A., 2011, "Categoremático/Sincategoremático", en Vega y Olmos 2011, pp. 90-91

Peacocke, C., 1988, "Understanding Logical Constants", Proceedings of the British Academy, vol. 73, pp. 191-200.

— , 1976, "What Is a Logical Constant?", Journal of Philosophy, vol. 73, pp. 221-240.

Peirce, C.S., 1932, Collected Papers of Charles Sanders Peirce, vol. II. Elements of Logic, ed. Charles Hartshorne y Paul Weiss, Harvard University Press, Cambridge, Mass.

Pelletier, F.J., 1999, “A Brief History of Natural Deduction”, History and Philosophy of Logic, vol. 20, pp. 1-31. 
Prior, A., 1976, “What Is Logic?", Papers in Logic and Ethics, University of Massachusetts Press, Amherst.

— 1960, "Roundabout Inference Ticket", Analysis, vol. 21, pp. 38-39.

Ramsey, F.P., 2005, Obra filosófica completa, ed. M.J. Frápolli, Comares, Granada.

_ , 1929/2005, "Proposiciones generales y causalidad", en Ramsey 2005, pp. 421-441.

— , 1928/2005, "Universales de ley y de hecho", en Ramsey 2005, pp. $415-420$.

Read, S., 2003, "Logical Consequences as Truth-Preservation", Logique et Analyse, pp. 183-184, 479-493.

Recanati, F., 2010, Truth-Conditional Pragmatics, Oxford University Press, Oxford.

— 2007, Perspectival Thought. A Plea for (Moderate) Relativism, Oxford University Press, Oxford.

—_, 2004, Literal Meaning, Cambridge University Press, Cambridge.

_. 2002, "Unarticulated Constituents", Linguistic and Philosophy, vol. 25, pp. 299-345.

—, 2001, "What Is Said", Synthese, vol. 128, pp. 75-91.

—_ 1993, Direct Reference. From Language to Thought, Blackwell, Oxford.

Ryle, G., 1954/1969, Dilemmas. The Tarner Lectures 1953, Cambridge University Press, Cambridge.

— 1949/2000, The Concept of Mind, Penguin Books, Londres.

Schroeder, M., 2008, Being For: Evaluating the Semantic Program of Expressivism, Oxford University Press, Oxford.

Sellars, W., 1968, Science and Metaphysics. Variations on Kantian Themes, Routledge and Kegan Paul, Londres.

Sher, G., 2003, "A Characterization of Logical Constants is Possible", Theoria, vol. 18, pp. 189-197.

— 1991, The Bounds of Logic. A Generalized Viewpoint, The MIT Press, Cambridge, Mass.

Sher, G. y R. Tieszen (comps.), 2000, Between Logic and Intuition. Essays in Honor of Charles Parsons, Cambridge University Press, Cambridge.

Sperber, D. y D. Wilson, 1986, Relevance. Communication and Cognition, Basil Blackwell, Oxford.

Stevenson, C.L., 1937, "The Emotive Meaning of Ethical Terms", Mind, vol. 46, no. 181, pp. 14-31.

Stevenson, J.T., 1961, "Roundabout the Roundabout Inference Ticket", Analysis, vol. 21, pp. 124-129.

Tarski, A., 1966/1986, "What Are Logical Notions?", History and Philosophy of Logic, vol. 7, pp. 143-154.

— 1936/1956, "On the Concept of Logical Consequence", Logic, Semantics, Metamathematics. Papers from 1923 to 1938, Clarendon Press, Oxford, pp. 409-420. 
Toulmin, S., 1958, The Uses of Argument, Cambridge University Press, Cambridge.

Van Benthem, J., 1984, "Foundations of Conditional Logic", Journal of Philosophical Logic, vol. 13, no. 3, pp. 303-349.

Vega Reñón, L. y P. Olmos Gómez (comps.), 2011, Compendio de lógica, argumentación y retórica, Trotta, Madrid.

Warmbrõd, K., 1999, "Logical Constants”, Mind, vol. 10, no. 431, pp. 503538.

Williams, C.J.F., 1992, “Towards a Unified Theory of Higher-Level Predication", Philosophical Quarterly, vol. 4, no. 169, pp. 449-464.

Wilson, D., 1975, Presupositions and Non-Truth Conditional Semantics, Academic Press, Londres.

Wittgenstein, L., 1922, Tractatus Logico-Philosophicus, trad. C.K. Ogden, Routledge and Kegan Paul, Londres/Nueva York.

Recibido el 16 de febrero de 2011; revisado el 7 de febrero de 2012; aceptado el 14 de mayo de 2012. 